\title{
Perspectiva Discursiva da Leitura \\ e o Professor em Processo de Formação Continuada
}

\author{
Discursive Perspective of Reading and the Teacher in the \\ Process of Continuing Education
}

\section{Maria Cleci VENTURINI *}

Resumo: O tema em tela, nesse artigo, é a formação continuada de professores concebidos como sujeitos do fazer pedagógico e a reflexão em torno de projetos centrados na leitura discursiva, alicerçada nos pressupostos teóricos da Análise de Discurso, de orientação francesa. Centramo-nos, naqueles que se inscreveram no Programa de Política Educacional (PDE), da rede Estadual de Ensino do Paraná e recortamos, dentre os nove projetos desenvolvidos nos últimos dois anos, sob nossa orientação, um projeto. Nosso objetivo, neste artigo, é dar visibilidade aos compromissos assumidos pelo sujeito-professor, dentre os quais destacamos a concepção do aluno como sujeito e o compromisso com os funcionamentos discursivos do texto, enquanto discurso.

Palavras-chave: Leitura discursiva; Sujeito-professor; Discurso.

Abstract: The theme in this article is about the teacher development of in-service teachers conceived as subjects of their own pedagogical practice as well as about the reflection on their pedagogical projects centred on discursive reading, having as theoretical framework the Discourse Analysis of French affiliation. We focus our study on a single project out of nine teaching projects developed in the last two years

* Doutorado em Estudos Linguísticos (UFSM). Professora do Departamento de Letras (DELET) da Universidade Estadual do Centro-Oeste UNICENTRO - PR. Contato: mariacleciventurini@hotmail.com. 
by nine in-service teachers, engaged in the Program of Educational Policy (PDE), offered to the public teaching sector in Paraná state. Our objective is this article to give visibility to the commitments assumed by the subject-teacher, which, among the many, we point out the conception of the student as subject as well as the commitment to the discursive functioning of the text while discourse.

Key-words: Discursive reading; Subject-teacher; Discourse.

\section{Considerações iniciais: delimitando fronteiras}

A reflexão acerca da leitura na perspectiva discursiva focaliza professores em processo de formação continuada, mais especificamente, os sujeitos-professores filiados ao PDE, Programa de Política Educacional, desenvolvido em parceria entre a Secretaria Estadual de Educação do Paraná - SEED e a Secretaria de Estado da Ciência, Tecnologia e Ensino Superior - SETI. O programa visa à formação continuada dos professores da Rede Estadual de Ensino e prioriza o diálogo entre os sujeitos-professores da Educação Superior e os da Educação Básica, por meio de um conjunto de atividades organicamente articuladas, que possibilitem a produção de conhecimento e resultem em mudanças qualitativas na prática pedagógica dos docentes. A seleção desses professores e a participação no programa é de responsabilidade da Secretaria Estadual do Paraná e se efetiva por meio de critérios pré-estabelecidos.

Os sujeitos-professores-PDE selecionados são orientados por docentes universitários de sua área, abarcando, na área de letras, o ensino de língua, a lingüística, a prática de ensino e a literatura em suas interfaces com a língua. O processo estrutura-se em quatro partes, em um espaço temporal de quatro semestres. A primeira ação realizada pelos docentes refere-se à escolha de um orientador, o qual lhes dará suporte teórico, indicando textos, promovendo discussões, possibilitando a elaboração, nos primeiros seis meses, de um projeto de ação, do qual resultam atividades práticas a serem aplicadas na escola no terceiro semestre. O projeto, depois de devidamente avaliado pelo professor orientador, é inscrito no GTR (Grupo de Trabalho), para atingir os demais professores da rede, por meio do moodle, do qual 
resultam discussões de questões teóricas e práticas, envolvendo projeto elaborado, anteriormente.

$\mathrm{Na}$ etapa seguinte, os professores retornam às escolas, com uma carga horária reduzida e desenvolvem o projeto de atividades práticas, já discutidas com o orientador e com os seus pares por meio do GTR. No último semestre, eles continuam o trabalho na escola e retomam as questões teóricas, as discussões dos GTRs e, sob a orientação do professor ligado à universidade, escrevem o artigo científico, que fecha o período de dois anos de formação continuada, pelo menos no que se refere ao programa PDE. O artigo escrito por eles é publicado no portal dia-a-dia da educação, mantido pela SEED.

O papel do professor universitário, nesse processo, é o de orientador dos sujeitos-professores-PDE, cujos projetos se filiem às suas linhas de pesquisa e aos projetos desenvolvidos por ele na universidade. Da posição-sujeito de orientador, centramos o trabalho de orientação na concepção de leitura como prática social e discursiva, pautada em sujeitos inscritos em formações discursivas, as quais determinam, segundo Pêcheux (1997), o que eles podem/devem fazer/ dizer, considerando o lugar social e a posição-sujeito ocupada. Os sujeitos a que nos referimos, nesse caso, são representados pelo professororientador, pelo professor PDE e, também, pelos sujeitos-alunos, cuja posição ocupada na formação social determina a leitura/interpretação/ compreensão e a leitura/escritura de textos.

A inscrição teórica e a filiação aos pressupostos teóricos da Análise do Discurso permitem-nos propor aos sujeitos-professoras um olhar diferenciado sobre o texto, considerando-o como uma unidade aberta a sentidos outros. Ancoramo-nos em Pêcheux e na teoria discursiva desenvolvida por ele na década de 70. No Brasil, Orlandi, juntamente com seus pares, relê Pêcheux e faz avançar pesquisas teóricas, pelas quais a Análise de Discurso se institucionalizou como uma disciplina, designada pela pesquisadora, como de entremeio (ORLANDI, 2004), tendo em vista os questionamentos em relação àquilo que a Linguística, a psicanálise e a teoria materialista do discurso deixam de fora.

O recorte temporal a que nos ativemos inicia em 2008, quando assumimos a orientação de três (3) professores - uma de Guarapuava, outra de Prudentópolis e, a terceira, de Porto Barreiro - e tem continuidade em 2009, com o ingresso, no grupo e no processo, de 
mais seis professores (duas de Pato Branco, uma de Pitanga, uma do Pinhão e duas de Guarapuava), totalizando nove projetos. No final de 2009 , as três professoras, que haviam iniciado o processo anteriormente, encerraram a sua participação. No segundo semestre de 2010, as demais professores implementaram a terceira parte do projeto, constituído pelo trabalho na escola, junto aos sujeitos-alunos e, a partir de então, dedicam-se à escritura dos artigos.

Das nove professores, apenas uma não optou pela leitura/ interpretação/compreensão e escritura do texto na perspectiva discursiva. Ela ancorou-se nos pressupostos teóricos da psicolingüística. Não nos opusemos, pois consideramos que o mais importante é a inscrição do sujeito-professor em uma formação discursiva, que indique uma orientação teórica, que sustente práticas consistentes e coesas, não mais pautado na leitura de "conteúdos" textuais, mas em efeitos de sentidos, decorrentes de processos, pelos quais importa saber "como o texto significa" e não os conteúdos que ele comporta. Nessa concepção de leitura, o sujeito-professor assume o lugar de sujeito do fazer pedagógico e adquire autonomia, tanto no que se refere à teoria, quanto à prática. $\mathrm{O}$ aluno, igualmente sujeito e, por isso, interpelado pela ideologia e atravessado pelo inconsciente, é o foco do trabalho. Sublinhamos a importância das condições de produção de toda materialidade textual, tendo em vista que elas concorrem para que determinados efeitos de sentidos se instaurem e outros não.

Assumimos, do nosso lugar e nossa inscrição na academia, que toda a atividade de leitura deve considerar os participantes do processo, os saberes que os constituem e a caminhada empreendida. Assim, os participantes do processo, as suas posições-sujeito, os lugares sociais e as FDs em que se inscrevem são o centro da atividade, tendo em vista serem eles a razão de todo fazer pedagógico. Ao ressalvar que apenas um, dentre os nove sujeitos-professores, não assumiu a perspectiva discursiva de leitura, não estamos sustentando que foi/é fácil mudar os rumos da prática pedagógica, nem que os sujeitos-professores se desprendem com facilidade da concepção de texto como "depósito" de conteúdos e do autor como alguém que tem a intenção "de". Ao contrário, dizemos que é um processo pautado no compromisso de usar, com menos freqüência, o livro didático e na busca por textos constitutivos do dia a dia, não só da escola, mas da formação social e 
da vida dos alunos, enquanto sujeitos. Para os sujeitos-professores não é usual, por várias razões, centrarem-se ao que é da ordem do vivido, daquilo que faz parte da vida sócio-histórica e política dos sujeitosalunos, enfim do que estrutura o cotidiano da educação e da escola.

Destacamos de início, em relação à metodologia, que os sujeitosprofessores-PDE com os quais temos trabalhado, nos dois últimos anos, não serão nominados. Descrevemos e analisamos um, dos nove projetos, devido ao espaço destinado a este texto, mas situamos todos eles, as temáticas em que se centram, destacando as redes de sentidos necessárias e determinantes para a leitura na perspectiva discursiva. Uma das razões para não descrever todos os projetos, é que os seis iniciados em 2009 estão em fase de implementação/conclusão e, descrevê-los, nessas condições, demandaria um tratamento metodológico diferenciado, permeado de suposições. Outra razão é que nem sempre os planejamentos são colocados em prática na íntegra; muitas vezes, há necessidade de reelaborar, de refazer percursos. Antes de iniciar a implementação, as professoras-PDE cumpriram as etapas precedentes, ou seja, submeteram seus projetos a seus pares nos GTRs e ao professor-orientador, a quem coube emitir parecer descritivo acerca da pertinência das atividades propostas. O percurso sinaliza para envolvimentos/filiações/identificações e, acima de tudo, para a coresponsabilidade do professor universitário na escola, e, por que não dizer, na rede estadual de ensino, pois o seu nome inscreve-se junto ao do sujeito-professor-PDE, circulando em todas as instâncias institucionais e sociais da educação pública do Paraná.

O corpus constitui-se, portanto, de um projeto desenvolvido em Guarapuava (sala de apoio em uma $5^{\text {a }}$ série). Recortamos a parte inicial da segunda etapa do Ensino Fundamental, destacando a possibilidade de enfocar a leitura de um outro lugar, independentemente do nível escolar. A identificação do projeto se dá por seus objetivos, pelas noções teóricas que o estruturam, pelas atividades realizadas e pelos domínios discursivos convocados nele/por ele. Enquanto orientadores filiados à Análise de discurso e, desse lugar que nos constitui, interessa-nos a prática discursiva e o percurso realizado, bem como as dificuldades dos sujeitos, diante de uma proposta centrada no discurso e nos efeitos decorrentes dessa escolha. Assumimos que a proposta analisada não está concluída e nem se constitui como resultado, mas como processo, 
segundo Pêcheux (1997, p. 16), "sistema de relações, substituições, paráfrases, sinonímias, etc., que funcionam entre elementos linguísticos - "significantes"- em uma formação discursiva dada". As palavras do autor remetem à base linguística e ao processo discursivo ideológico que permeia o discurso. Enfim, de um trabalho, nessa perspectiva, não se espera produtos, mas efeitos, conforme processo discursivo descrito pelo autor em tela.

\section{Pressupostos teórico-metodológicos e a interpelação do professor-sujeito de sua prática}

Em relação ao programa e ao trabalho com sujeitos-professores, inseridos no processo de formação continuada, destacamos, de um lado, a título de ilustração e de conclusões preliminares, as dificuldade enfrentadas por eles nesse "retorno" à universidade, depois da experiência de vários anos sala de aula, de cargas horárias pesadas, da escassez de tempo para repensar a prática pedagógica. O retorno, por mais compensador que seja, faz com eles se depararem com uma proposta diferenciada e, com/por ela sintam necessidade de se desprenderem de antigas concepções e de certezas as quais demonstram a necessidade de alteração de um quadro que repete o mesmo e, não raras vezes, concebe a materialidade textual como pretexto para trabalhar conteúdos gramaticais. De outro, enfatizamos, em relação aos professores-orientadores, o desafio de olhar a escola e a prática pedagógica e de inscrever-se no processo como coparticipante, $\mathrm{O}$ trabalho de orientação implica o movimento da teoria, colocando-a em funcionamento, o que não é fácil. Esse olhar exige, muitas vezes, um recuo, tendo em vista o afastamento de um contexto idealizado e a entrada em práticas pedagógicas ligadas ao real, ao mundo normatizado e institucionalizado da escola. Vale dizer, entretanto que, apesar das dificuldades decorrentes da presença da escola na universidade, esse intercâmbio é de suma importância, especialmente, para os professores-universitários, que se querem/se dizem/se constituem como formadores de professores, tendo em vista a militância em licenciaturas. O trabalho nas licenciaturas, entretanto, não lhes garante a aproximação com o cotidiano escolar, o que é proporcionado pela participação no programa PDE. 
O presente texto estrutura-se, além da introdução e da conclusão, em mais duas partes, entrelaçando teoria e prática, embasada nos fundamentos teóricos da Análise do Discurso - a AD Brasileira centrada em Orlandi e nas discussões em torno dos projetos desenvolvidos pelos sujeitos-professores-PDE. Nosso objetivo é destacar as implicações pedagógicas, sociais e discursivas que a abordagem da leitura e da escritura, alicerçadas no que é exterior ao texto, dá visibilidade, especialmente, quando são colocados em tela conceitos relacionados com a língua na história e com o sujeito-professor como analista que, apesar de trabalhar e de preocupar-se com o saber linguístico, não deve/ não pode centrar-se apenas nesse saber.

Os conceitos de texto, discurso, leitura e escritura ajudam a estruturar práticas discursivas, à medida que se imbricam e trazem, para o eixo da formulação, concepções de sujeito, de autor e de autoria, cujos funcionamentos se constituem pela interpelação ideológica e pelo atravessamento do inconsciente e sinalizam para o sentido das palavras em relação a formações discursivas e a processos de subjetivação teorizados, inicialmente, por Pêcheux. As materialidades, passíveis de serem lidas a partir dos pressupostos teórico-metodológicos da Análise do Discurso, de orientação francesa foram, num primeiro momento, segundo Courtine (1981), as ligadas ao político. A orientação brasileira dada ao campo disciplinar constitui-se pela prática de leitura/ interpretação de toda e qualquer materialidade, incluindo as não textuais, estruturadas pelo que designamos em trabalho anterior (VENTURINI, 2009), de enunciados-imagem, em que os sentidos e a possibilidade de leitura pelo que significa antes em outro lugar, os pré-construídos.

A proposição da leitura na perspectiva discursiva pelo sujeitoprofessor, em sua prática pedagógica, exige dele decisões importantes. A primeira delas consiste na concepção do aluno como sujeito e, a segunda, em sua inscrição como analista de discurso, demandando a saída de um lugar confortável para assumir uma postura política. As duas decisões se pressupõem e se reclamam, pois a concepção do aluno como sujeito, implica a inscrição dele em formações discursivas, do que decorre a tomada de posição na leitura/interpretação/ compreensão de textos, tendo em vista que o sentido das palavras, segundo Pêcheux (1997, p. 160), “não existe em 'si mesmo' (isto é, na relação transparente com a literalidade do significante), mas, ao 
contrário, é determinado pelas posições ideológicas que estão em jogo no processo sócio-histórico no qual as palavras, expressões e proposições são produzidas (isto é reproduzidas)." O sentido ocorre a partir de sujeitos interpelados pela ideologia e atravessados pelo inconsciente que se filiam a lugares sociais e se posicionam teoricamente em torno da não-transparência dos sentidos e não opacidade da língua. A inscrição do sujeito-professor como analista do discurso implica, de acordo com Orlandi (2001), o não preenchimento do lugar da interpretação para o outro, mas a construção de reflexões e de escutas, enfim, de caminhos que propiciem ao sujeito-leitor a percepção da opacidade do texto, não para atravessá-lo, mas para realizar, por meio de materialidades discursivas a ponte necessária entre textos e discursos.

Quando assume as duas posições descritas - concepção do aluno como sujeito e a inscrição como analista do discurso - o sujeitoprofessor "leva em conta a materialidade da linguagem, isto é, sua não-transparência e coloca a necessidade de construir um artefato para trabalhar sua espessura semântica - linguística e histórica - em uma palavra, sua discursividade." (ORLANDI, 2001, p. 21). Junto ao programa PDE e na posição-sujeito de orientadores dos projetos desenvolvidos por esses sujeitos, sublinhamos, alicerçados na $\mathrm{AD}$, o discurso como "um processo contínuo que não se esgota em uma situação particular", dando visibilidade para o trabalho da memória, enquanto eixo vertical, atualizando o intradiscurso, tendo em vista que "outras coisas foram ditas antes e outras serão ditas depois. O que temos são sempre "pedaços", "trajetos", estados do processo discursivo", conforme Orlandi (2001, p. 14).

A afirmação de Orlandi, acima citada, foi o argumento usado junto aos sujeitos-professores-PDE para demonstrar que o sentido sempre pode ser outro. Pêcheux (1997, p. 160) reitera que o sentido de palavras, expressões, proposições mudam "segundo as posições sustentadas por aqueles que as empregam". Com isso, mobiliza as formações ideológicas e a formação discursiva decorrente delas, a qual, de acordo com o mesmo autor, regula o que o sujeito, a partir da posição assumida, pode/deve dižer e também, ou não pode/não deve dizer.

Os pressupostos teóricos e as ancoragens destacadas nos permitem assumir que os sentidos e, em decorrência deles, a leitura e a 
interpretação, dependem do que é exterior ao texto, de discursos fundantes e do funcionamento da memória. Assim, sinalizamos para o funcionamento do texto como unidade de análise do discurso, constituída, imaginariamente, por começo, meio e fim. Os pressupostos assinalados foram destacados junto aos sujeitos-professores-PDE. Em 2008, foram propostos e implementados na totalidade três projetos: dois ancorados nos pressupostos da Análise do Discurso e, o terceiro, filiado aos pressupostos teóricos da psicolingüística. Em 2009, tiveram início mais seis projetos, os quais estão sendo aplicados nas escolas, conforme destacamos anteriormente. Entretanto, para fins de análise, recortamos o projeto desenvolvido em Guarapuava e, apenas citamos os oito projetos já referidos (três concluídos e seis em andamento), relacionando-os aos domínios discursivos a que eles remetem. Iniciamos pelo projeto recortado para análise e encerramos com a descrição dos demais projetos.

\section{Leitura do espaço urbano: mídia e crônicas do cotidiano}

Agrupamos, na segunda parte, três temas que, de alguma forma, se relacionam com o espaço urbano, o qual significa e é significado pelos sujeitos que o habitam. Na perspectiva discursiva, de acordo com Orlandi (2001, p. 185) “o espaço urbano pode ser considerado como um espaço material que funciona como um sítio de significação que demanda gestos de interpretação particulares. Um espaço simbólico trabalhado em/pela história, um espaço de sujeitos e de significantes". Alicerçados nos pressupostos teóricos descritos, agrupamos, em um mesmo lugar e descrevemos as atividades e implicações discursivas, de um projeto que engloba a mídia, o espaço urbano e o consumismo presente nas crônicas do cotidiano. O sujeito-professor-PDE, em tela, trabalha com uma $5^{\mathrm{a}}$. série (classe de apoio) em uma escola de Guarapuava e centra as reflexões na mídia como constituidora de desejos, nem sempre satisfeitos em relação aos sujeitos-alunos, abordando, assim, o consumismo.

A motivação e a entrada no tema "espaço urbano" se dá por meio de uma constatação que vem do senso comum, portanto inscrita na ordem da naturalidade, ou seja, o fato de todos vivermos em um espaço social, no qual o cotidiano se estrutura em torno de direitos e 
de deveres. Como se trata de uma $5^{\text {a }}$. Série, não há como referir à teoria, especificamente, à noção formação discursiva, que determina o que o sujeito, pela posição ocupada, pode/deve não pode/não deve dižer/ fazer. Assim, são enfocados os direitos e deveres como práticas que recobrem a disciplinarização do sujeito inscrito em FDs. De acordo com o sujeito-professor-PDE "as placas, de um lado, orientam o comportamento dos sujeitos, dizendo o que podem ou não fazer. A mídia, de outro, prioriza o consumo, tornando visíveis e atraentes, no espaço urbano, os mais variados produtos". Depois dessa motivação, os alunos buscam os sentidos da palavra mídia no site < http:// michaelis.uol.com $>$.

A primeira materialidade apresentada a eles é $\mathbf{3}^{\mathbf{a}}$. pessoa do plural, letra e música do grupo Engenheiros do Hawaii, para situar no espaço da sala de aula a publicidade (trabalho da mídia) e destacar as formas de interpelação ideológica do sujeito urbano pelos meios de comunicação de massa, como poder, que constitui evidências de que se deve priorizar o " ter em lugar do ser". O sujeito-professor encaminha as discussões e propõe reflexões em torno do que "plural". Em seguida, destaca o funcionamento das pessoas do discurso - eu/ nós/eles - e os efeitos de sentido do uso dessas pessoas do discurso na materialidade textual. Explora, também, o espaço da contradição decorrente de palavras que se relacionam pelo traço de antonomia saúde/doença, comprar/vender, remédio/cigarro - nas propagandas veiculadas pela televisão, a partir das quais faz questionamentos em torno da aparência dos sujeitos protagonistas dos enunciados publicitários. Centra os questionamentos nas mensagens, com vistas a dar visibilidade aos efeitos de sentidos de sucesso ou de fracasso presentes nos enunciados analisados. A leitura realizada possibilita destacar os imaginários constituídos em torno do consumidor/ telespectador e o modo como esses imaginários se estruturam. O sujeito-professor encaminha as discussões para os desejos desencadeados no sujeito-telespectador, buscando ler/interpretar/ compreender, nessas materialidades, os discursos que retornam e sustentam o dizer no fio do discurso.

Como sinalizamos anteriormente, trata-se de uma $5^{\text {a }}$. Série e, por isso, os fundamentos teóricos da Análise de Discurso não são mobilizados. Há necessidade, então, de encaminhar para materialidades 
que instaurem a construção de redes parafrásticas, colocando em suspenso o sentido das palavras e os efeitos delas. Os questionamentos permitem dar visibilidade ao suporte em que a materialidade circula, ao contexto sócio-histórico de sua produção, buscando desestabilizar os sentidos postos/sedimentados na mídia e no espaço urbano. As reflexões/discussões sinalizam para o que Orlandi (2002) chama de "relações de sentido", quando diz que uma palavra usada no lugar de outra, pode mudar o sentido ou não, porque mobiliza outras memórias e discursos, sentenciando enfim, que "as palavras não são indiferentes ao sentido". Ainda em relação a esse texto, os sujeitos-alunos buscam saber quem são os Engenheiros do Hawaii, com vistas a identificar as particularidades e filiações do grupo a determinadas FDs. Outro aspecto abordado, diz respeito ao contexto sócio-histórico em que a letra da música foi composta, com vistas a pensar se as condições de produção do texto, tanto em sentido restrito, como em sentido amplo, são relevantes para a leitura, enfim para a interpretação/compreensão de textos.

$\mathrm{Na}$ aula seguinte, são retomadas as designações, etiquetas, marcas dos produtos, falsificações e, após, é apresentado o texto de Carlos Drummond de Andrade Eu etiqueta para trabalhar o efeito de "coisificação" do sujeito urbano, instaurando, por meio desse processo, o efeito de sentido de "homem-anúncio itinerante", à medida que carrega rótulos e marcas nas roupas que veste. Assim como no texto anterior, há encaminhamento para as condições de produção, para pensar o funcionamento e efeito autor/autoria. O sujeito-professor, então, discute as relações parafrásticas constituídas entre os dois textos, bem como as redes de memória instauradas por meio de outros discursos, que ressoam neles/por eles. A atividade realizada sinaliza para o funcionamento do texto e do trabalho da língua na história, destacando, no dizer de Orlandi (2001, p. 110), que "o texto tem em suas margens muitos outros textos: as famílias parafrásticas [....] indicam outras formulações - textualizações - possíveis no mesmo sítio de significação, mas que se organizam em diferentes espaços significantes".

Esse modo de enfocar a leitura mobiliza o trabalho da ideologia e o fato de que em cada texto as maneiras de dizer são diferentes e que essas formas diferentes de dizer o mesmo constituem "evidências da forma como a política do dizer inscreveu a memória no interior de 
sua formulação" (ORLANDI, 2001, p. 111), e que o texto "é sempre um conjunto de formulações entre outras possíveis, movimento do dizer face ao silêncio". Orlandi (2001) pensa o texto como "horizonte discursivo do ‘a dizer' e não o vazio”. As atividades de leitura têm continuidade, no mesmo eixo temático e, o terceiro texto apresentado é a Moça tecelã , de Marina Colassanti. A referida materialidade textual diferencia-se das anteriores, mas reconstrói as mesmas redes de sentido em torno da mídia, fazendo ressoar, no eixo da formulação, as mesmas questões suscitadas entre o "ser e ter", tratando-as, entretanto, como crônica do cotidiano. Nesse texto, são mobilizados saberes em torno do "querer" desenfreado em torno de bens materiais, os quais apagam, para o sujeito, o direito/desejo de ser feliz, sem compromissos com a ordem do real. O sujeito interpelado pela ideologia capitalista constitui evidências de que o desejo de "ter" sempre mais bens materiais causa insatisfação, tanto para o sujeito do desejo (nesse texto, o marido), como para quem satisfaz esses desejos (a moça tecelâ). Na ordem da ficção, ocorre a simulação de uma realidade urbana e, o impasse se resolve quando a moça "destece" o marido, descontruindo a rede construída em torno do desejo de "ter" e da insatisfação que esse desejo suscita, principalmente, quando um dos sujeitos ocupa a posiçãosujeito de oprimido e explorado.

Até o presente momento, o sujeito-professor recortou e trabalhou três materialidades discursivas e mostrou as redes parafrásticas existentes entre essas três textualidades, os modos como, em cada uma delas, se constitui um conjunto de relações significativas, particularizadas em cada texto, como uma unidade imaginariamente fechada. Cada unidade, imaginariamente fechada, encaminha para discursos, segundo Orlandi (2001, p. 88), pela relação com as formações discursivas em suas diferenças, constituindo a historicidade do texto e dos sujeitos. A moça tecelã pode encaminhar para o discurso feminino, em que o sujeitomulher se submete aos "caprichos" de um marido dominador, tornando-se escrava dele, à medida que aceita e satisfaz os seus desejos consumistas ou para outros sentidos, dependendo da inscrição do sujeito em FDs. No trabalho realizado pelo sujeito-professor-PDE, esse texto remete, de um lado, ao discurso da mídia e, de outro, a partir da imagem presente na capa do livro e do enunciado " era uma vez", aos contos de fadas e, consequentemente, ao imaginário em torno 
de princesas, sinalizando para a ficção. Outra atividade em relação a esse texto, assim como aconteceu com os dois anteriores, foi a pesquisa acerca de Marina Colassanti, autora do texto. A atividade possibilita o conhecimento e, possivelmente, a leitura de textos da mesma autora e a retomada das condições de produção do texto trabalhado, priorizando o contexto sócio-histórico da escritura do texto, bem como a relação da obra com outras e, também, com temáticas relacionadas à mídia.

As discussões efetivadas até então fazem com que o sujeitoprofessor-PDE redirecione as reflexões e aborde, mais especificamente, o espaço urbano. O centro das discussões é, então, a ordem e a organização da cidade, as interdições materializadas por placas que "dizem" o que os sujeitos podem/devem fazer e separa o público e o privado. A mídia é visibilizada como instituição que exerce poder em relação aos sujeitos da formação social, ditando regras e normas de comportamento. Nesse fazer, à medida que pensa o espaço privado, da casa, da vida em família, o sujeito-professor destaca o espaço público, questionando se o que é ordem da casa desliza para o público. $\mathrm{O}$ questionamento objetiva dar visibilidade às relações familiares, ao que se pode ou não fazer quando se vive em família ou em grupos mais fechados, abordando as formas como os sujeitos se constituem em torno do outro (aquele que vive/convive com ele) e do Outro (o inconsciente). A culminância das atividades se dá por meio de duas atividades. A primeira é a proposta de textualização de placas pelos sujeitos-alunos, as quais seriam colocadas na porta dos seus quartos ou em outros ambientes da casa. A segunda, é a escritura e depois a leitura de textualidades em torno de passeios pela cidade. O objetivo da segunda atividade é chamar a atenção deles para as placas, enquanto textos que determinam o funcionamento do espaço urbano, que é público, mas não isento de determinações e coerções institucionais.

As atividades desenvolvidas suscitaram, no sujeito, que assume o lugar de professor e, desse lugar escolhe/determina as temáticas de suas aulas, um certo estranhamento, tendo em vista o fato de os sujeitosalunos não falarem da cidade e dos espaços que a constituem. Ao contrário, falaram deles mesmos, do que eles leram/interpretaram/ compreenderam da cidade, mais especificamente, de seus "desejos", do que acontecia com eles, nesses espaços, do que comiam/ 
compravam/levavam nos passeios. O sujeito-professor pôde, então, ler/interpretar/compreender que as crianças, assim como ele, também são sujeitos das suas leituras, enfim das atividades por eles realizadas e como tais significam e são significados pela cidade, tomado-a como da ordem da realidade e não na da idealidade. Compreendeu, igualmente, que os sujeitos inscrevem-se em determinadas formações discursivas e não em outras. A inscrição em FDs resulta em leituras diferenciadas, na mobilização de discursos antagônicos, que se repelem e, às vezes, se imbrincam.

Em 2008 e 2009, orientamos nove projetos, todos em torno da leitura: oito deles inscreveram-se na Análise do Discurso, de orientação francesa e um na Psicolingüística. O sujeito-professor filiado à Psicolinguística, assim como os demais, observou que há uma distância considerável entre o que os sujeitos-alunos "sabem" sobre determinadas temáticas e aquilo que os coordenadores do processo exigem deles. $\mathrm{O}$ professor, que desenvolveu esse projeto, trabalha na cidade de Porto Barreiro, interior do Paraná, e o seu grupo de alunos constitui-se de sujeitos advindos de pequenas propriedades rurais, e alguns pertencem ao MST. Devido a essas condições, elegeu como tema os super-heróis e trabalhou com diversas materialidades: imagens, filmes, músicas, obras literárias, programas de televisão. O objetivo foi, na terminologia da Psicolinguística, abrandar a defasagem entre o que eles sabem e o que não sabem, partindo do pressuposto de que o conhecimento de mundo é constitutivo da leitura. Destacamos que os demais projetos (oito) inscreveram-se na teoria discursiva. A professora de Prudentópolis elegeu o discurso político e o seu objetivo foi priorizar a leitura como uma prática discursiva entre sujeitos, a partir da memória (interdiscurso) e do intradiscurso (eixo da formulação), aplicando-o ao terceiro ano do Ensino Médio.

Os projetos descritos mais acima foram concluídos. Passamos a seguir aos projetos em andamento, que são seis. Dois sujeitosprofessores são de Pato Branco (PR) e enfocam a leitura e a escritura a partir do espaço urbano. O primeiro projeto centra-se nas crônicas de Luis Fernando Veríssimo, mais especificamente na leitura/análise de crônicas do escritor, ressaltando os processos discursivos, o efeitoleitor e o efeito-autor desencadeados pelo humor, que viabiliza o efeito de crítica social. As atividades propostas contemplam textos de outros 
autores, buscando dar visibilidade ao interdiscurso, enquanto memória que atualiza o sentido nas crônicas de Veríssimo e se constitui pelos "já-ditos", reconhecidamente marcados em sua produção. O segundo sujeito-professor, lotado no mesmo núcleo, propôs atividades a partir da leitura de contos que abordam o contexto urbano. Os textos são de autores renomados e contemporâneos, e as materialidades trabalhadas são letras de músicas, contos imagéticos estruturadores do discurso urbano e que sinalizam para as implicações sociais e discursivas da leitura.

O terceiro sujeito-professor pertence ao Núcleo de Pitanga e propõe a leitura em torno do discurso publicitário, enfocando as materialidades textuais pertencentes a esse domínio, junto aos estudantes da EJA (educação de jovens e adultos). O eixo estruturador do trabalho é a noção condições de produção, mais especificamente, as condições de produção e a circulação dessas materialidades, sinalizando que o sentido sempre pode ser outro e que o texto comporta o dizível, mas também o indizível, o que lhe é exterior (sua historicidade). Os outros três projetos são de sujeitos-professores-PDE lotados no núcleo de Guarapuava, duas da sede e uma da cidade de Pinhão. Um, dentre os sujeitos-professores lotados na sede, busca intervir pedagogicamente no ensino e aprendizagem a partir da leitura do discurso Jornalístico, em artigos de opinião. O objetivo é analisar e dar visibilidade à relação autor/leitor. O segundo optou por trabalhar com contação de histórias e recortou versões de contos de fadas para, a partir deles, dar visibilidade ao funcionamento da memória e aos discursos que retornam e fazem trabalhar outros espaços de memória. Por fim, o sujeito-professor da cidade de Pinhão, tendo em vista que os sujeitos-alunos com os quais trabalha são do campo e estudam na Escola Familiar Rural, optou por trabalhar com letras de músicas, estruturando o trabalho em torno do funcionamento discursivos dessas materialidades. Entendemos que as propostas se inscrevem na perspectiva discursiva e, assim como as três concluídas, servem de incentivo para aqueles que permanecem no lugar "comum", na análise de conteúdo, em detrimentos de processos discursivos. 


\section{Entrelaçando a prática analítica aos pressupostos teóricos: possível conclusão}

Concluímos, pela análise do projeto desenvolvido em Guarapuava e pela descrição dos demais oito projetos, que o sujeitoprofessor deve, caso opte pela leitura na perspectiva discusiva, tomar duas decisões importantes. A primeira dessas opções, é tomar o aluno como sujeito e não mais como sujeito empírico participante de um processo ensino-aprendizagem fechado em seus próprios objetivos. A segunda decisão refere-se ao próprio sujeito-professor, ou seja, à inscrição dele na FD dos analistas do discurso e, com isso, esquecendose /lembrando-se do que o estrutura e o mantém no lugar que ocupa. Nesse fechamento de texto, priorizamos, portanto, os esquecimentos relacionados a sujeitos, os quais estruturam a leitura discursiva, à medida que "mascaram", para o sujeito, a interpelação pela ideologia e o atravessamento pelo inconsciente.

O funcionamento do sujeito-aluno, enquanto sujeito e a constatação de que o "sentido sempre pode ser outro", dá visibilidade às reflexões de Pêcheux (1997, p. 160) em relação ao sentido das palavras, como decorrente das formações discursivas e ideológicas e das posições-sujeito sustentadas por sujeitos, sendo que esta última reproduz o processo sócio-histórico da inscrição do sujeito em formações discursivas. Disso tudo, pode-se dizer, então, que na leitura discursiva, o sentido nunca é único e que os textos encaminham para "outros" textos e neles ressoam, igualmente, "outros" discursos, nem sempre pensados pelos sujeitos-professores, enquanto coordenadores do processo. Nesse movimento, o sentido não pode ser determinado a priori, apesar de, na formação discursiva dos sujeitos-professores, isso ser visto como possível, constituindo-se como uma leitura institucionalizada.

Ainda em relação a esse projeto, enquanto sujeito-orientador do processo, percebemos que, no trabalho com a leitura, o sujeitoprofessor (em geral, não só o do PDE), se constitui pela ilusão de que os sentidos "estão" nele, esquecendo-se do trabalho da memória e também de que, como diz Orlandi (2002), "quando nascemos as palavras já tinham sentido". Ele, assim como os demais sujeitos do 
discurso, constituem-se pelos esquecimentos, chamados por Pêcheux (1997, p. 173) de esquecimento no. 1 e de esquecimento no. 2. Este último decorre da seleção feita pelo sujeito no interior de uma formação discursiva que o domina, "isto é, no sistema de enunciados, formas e sequências que nela se encontram em relação de paráfrase - um enunciado, forma ou sequência e não outro, que, no entanto, está no campo daquilo que se poderia chamar de formulação-reformulação na formação discursiva considerada”. Por esse esquecimento, segundo o autor, o sujeito tem impressão da realidade de seu pensamento. A impressão decorre da abertura constitutiva do sujeito e da qual ele "se utiliza constantemente, através do retorno sobre si do fio de seu discurso, de antecipação de seu efeito e da consideração da discrepância introduzida nesse discurso de um outro (como próprio outro) para explicitar e se explicitar a si mesmo o que ele diz e 'aprofundar o que ele pensa" (PÊCHEUX, 1997, p. 174). Para Orlandi (2002, p. 35), esse esquecimento é da ordem da enunciação (pré-consciente) e constitui, para o sujeito, a ilusão referencial, dita por Pêcheux, como impressão de realidade do pensamento, pela qual ilusoriamente há uma relação 'natural' entre as palavras e as coisas.

O esquecimento, chamado por Pêcheux (idem) de esquecimento no. 1, é da ordem do inconsciente, do não-dito que determina todo o dizer, mas não é acessível ao sujeito. Segundo o autor (p. 176), decorre da não consciência do sujeito daquilo que lhe é exterior, pela inscrição em formações discursivas e "isso em condições tais que todo acesso a esse exterior pela reformulação lhe seja proibido por razões constitutivas referentes às relações de divisão-contradição que atravessam-organizam o 'todo complexo das formações discursivas' em um momento histórico dado" (PÊCHEUX, 1997, p. 176-7). Por esses esquecimentos, destaca o efeito da forma-sujeito do discurso e como ele mascara o objeto daquilo que ele designa de esquecimento no. 1, "pelo viés do funcionamento do esquecimento no. 2", Desse modo, segundo o autor, "o espaço de reformulação-paráfrase" próprio de uma FD constitui determinadas formações discursivas como o lugar em que se constitui o que Orlandi (2004) chama de "língua imaginária", isto é, estruturada por um corpo verbal institucionalmente regulado por substituíveis, que parecem exercer o recobrimento de um vocábulo por outro. Orlandi (2002) retoma esse esquecimento e o define pelo sonho adâmico constitutivo do sujeito, de ser a "origem do dizer". 


\section{Referências}

COURTINE, Jean-Jacques. Analyse $d u$ discours politique (le discourse communiste adressé aux chrétiens). Paris: Langage 62, juin 1981.

ORLANDI, Eni Pulcinelli. (Org.). Cidade atravessada: os sentidos públicos no espaço urbano. Campinas: Pontes, 2001.

2003.

. Análise de discurso: princípios e procedimentos. São Paulo: Pontes, Interpretação: autoria, leitura e efeitos do trabalho simbólico. Campinas: Pontes, 2004.

PÊCHEUX, Michel. Semântica e discurso: uma crítica à afirmação do óbvio/ Michel Pêcheux. Trad. Eni Pulcinelli Orlandi [et AL.]. São Paulo: Editora da Unicamp, 1997.

VENTURINI, Maria Cleci. Imaginário urbano: espaço de rememoração/ comemoração. Passo Fundo/RS: Editora da UPF, 2009. 